\title{
The competitive N-methyl-D-aspartate (NMDA) antagonist CGS 19755 attenuates the rate-decreasing effects of NMDA in rhesus monkeys without producing ketamine-like discriminative stimulus effects
}

\author{
Charles P. France ${ }^{1, *}$, James H. Woods ${ }^{1}$ and Paul Ornstein ${ }^{2}$ \\ ' Departments of Psychology and Pharmacology, University of Michigan, Ann Arbor, MI 48109-0626 \\ and $^{2}$ Lilly Research Laboratories, Indianapolis, IN 46285, U.S.A.
}

Received 18 July 1988, revised MS received 28 September 1988, accepted 18 October 1988

\begin{abstract}
The purported competitive excitatory amino acid antagonist CGS 19755 was compared to the non-competitive antagonists ketamine and MK-801 in three rhesus monkeys discriminating between $1.78 \mathrm{mg} / \mathrm{kg}$ of ketamine and saline while responding under a fixed-ratio 100 schedule of food presentation. MK-801 substituted completely for the ketamine discriminative stimulus and was 32 times more potent than ketamine as a discriminative stimulus. CGS 19755 was studied using single and cumulative dosing procedures up to a dose of $10.0 \mathrm{mg} / \mathrm{kg}$; for all conditions, CGS 19755 produced responding exclusively on the saline lever and had only modest rate-decreasing effects. N-Methyl-Daspartate administered alone also did not produce ketamine-appropriate responding but did decrease response rates in a dose-related manner. N-Methyl-D-aspartate eliminated responding in all monkeys at doses of $5.6-10.0 \mathrm{mg} / \mathrm{kg}$. MK-801 and ketamine antagonized the rate-decreasing effects of N-methyl-D-asparate, however, ketamine was most effective as an antagonist at doses that decreased response rates when administered alone. CGS 19755 also attenuated the rate-decreasing effects of $\mathrm{N}$-methyl-D-aspartate and shifted the $\mathrm{N}$-methyl-D-aspartate dose-effect curve more than 5-fold to the right. The magnitude of antagonism of $\mathrm{N}$-methyl-D-aspartate appeared to be somewhat greater with CGS 19755 than with MK-801 or ketamine. Thus, a competitive (CGS 19755) and some non-competitive (MK-801 and ketamine) excitatory amino acid antagonists can attenuate the rate-decreasing effects of $\mathrm{N}$-methyl-D-aspartate. Surprisingly, the results suggest that antagonism of N-methyl-D-aspartate is not sufficient to produce ketamine-like discriminative stimulus effects under these conditions in rhesus monkeys.
\end{abstract}

NMDA (N-methyl-D-aspartate); MK-801; CGS 19755 (1-(cis-2-carboxypiperidine-4-yl)-methyl-1-phosphonic acid); Schedule-controlled responding; Drug discrimination; (Rhesus monkey)

\section{Introduction}

It has been proposed that excitatory amino acid (EAA) neurotransmission is an important neurochemical system mediating the behavioral effects

\footnotetext{
* To whom all correspondence should be addressed: Department of Pharmacology, M6322 Medical Science I Building, University of Michigan Medical School, Ann Arbor, MI 48109-0626, U.S.A.
}

of phencyclidine (PCP)-like drugs (e.g. Koek and Woods, 1988). There is a considerable amount of evidence that supports the notion that antagonism at N-methyl-D-aspartate (NMDA)-associated ion channels is one mechanism of action of PCP-like drugs in vitro, however, there has been little direct evidence regarding interactions between NMDA and presumed NMDA antagonists in vivo. The present study was designed to compare the behavioral effects of a purported systematically active competitive NMDA antagonist CGS $19755((+)$ - 
5-methyl-10,11-dihydro-5H-dibenzo(a,d)cyclohepten-5,10-amine maleate; Lehmann et al., 1987) to those of the non-competitive NMDA antagonists MK-801 (1-(cis-2-carboxypiperidine-4-yl)methyl1-phosphonic acid; Wong et al., 1986) and ketamine. The behavioral implications of the differentiation between competitive and non-competitive antagonists, as defined electrophysiologically, is a relatively unexplored area of research (e.g. Koek and Woods, 1987).

The discriminative stimulus effects of ketamine are well characterized, and it has been shown that a wide variety of compounds (e.g. PCP) that share other behavioral effects (e.g. anesthesia) with ketamine also substitute for the ketamine discriminative stimulus (Balster and Willetts, 1988; Koek et al., 1988). Recently the non-competitive NMDA antagonist MK-801 (Wong et al., 1986) has been shown to share discriminative stimulus effects with ketamine and with PCP. MK-801 substituted completely for the PCP discriminative stimulus in rats (Willetts and Balster, 1988a) and in pigeons (Koek et al., 1988) but substituted partially (65-85\%) for ketamine in rhesus monkeys (Koek et al., 1988). Perhaps due to their poor availability centrally when administered systemically, competitive NMDA antagonists have not been studied extensively in primates (Woods et al., 1987). In the present study the discriminative stimulus effects of the purported competitive EAA antagonist CGS 19755 (Bennett et al., 1987; Boast et al., 1987; Lehmann et al., 1987) were assessed in rhesus monkeys discriminating between subcutaneous (s.c.) injections of ketamine and saline. Ketamine, MK-801, and CGS 19755 were also compared for their capacity to attenuate the ratedecreasing effects of NMDA.

\section{Materials and methods}

\subsection{Subjects}

Three adult, male rhesus monkeys (Macaca mulatta) trained previously to discriminate between s.c. injections of $1.78 \mathrm{mg} / \mathrm{kg}$ of ketamine and saline were housed individually with free access to water. In addition to food received dur- ing experimental sessions, monkeys received Purina Monkey Chow and fresh fruit post-session in the home cage.

\subsection{Apparatus}

During experimental sessions monkeys were seated in Plexiglas primate chairs located inside ventilated, sound-attenuating chambers provided with continuous white noise. On one wall of the chamber were located an array of stimulus lights as well as two response levers and a food receptacle that were within easy reach of a seated monkey. A food hopper was mounted on the outside of the chamber and delivered food (300 mg Noyes banana-flavored pellets) to a receptacle via a plastic tube. Experiments were controlled and data recorded with microprocessors (IBM PCjr).

\subsection{Procedure}

Sessions of $0.5-1.5 \mathrm{~h}$ were conducted five days per week and consisted of 2-6 discrete, 15-min cycles. Each cycle consisted of a 10-min time out during which the chamber was dark and lever presses had no programmed consequence, and a 5-min response period during which the chamber was illuminated by pairs of $7 \mathrm{~W}$ blue and green lights and food was available under a fixed-ratio (FR) 100 schedule. Completion of 100 lever presses on the injection-appropriate lever (left lever, ketamine-appropriate; right lever, saline-appropriate) resulted in delivery of 10 food pellets. An incorrect response reset the FR requirement to 100 for the correct lever. Injections of drug or saline were made during the first minute of the 10-min time out. The training dose of ketamine was injected only once per day and that cycle was preceded by $0-4$ saline-injection cycles. For some training sessions ketamine was not administered and monkeys received an injection of saline prior to each of 2-6 cycles.

Test sessions were conducted every 2-3 days so long as stimulus control was maintained in the intervening training sessions according to the criteria: fewer than 100 responses on the incorrect 
lever and at least $90 \%$ of responses on the correct lever for all cycles. Test sessions were identical to training sessions except that 100 consecutive responses on either lever produced food and various doses of other drugs were administered during the first minute of each time out. For some studies increasing doses of drug were administered over successive cycles (i.e. cumulative dosing) and for other studies a single dose of drug was administered $0-24 \mathrm{~h}$ prior to the beginning of a test session.

CGS 19755 was compared to MK-801 and ketamine using two behavioral endpoints. First, the capacity of CGS 19755 and MK-801 to substitute for the ketamine discriminative stimulus was studied. Second, the capacity of CGS 19755, MK-801 and ketamine to antagonize the effects of NMDA on FR responding for food was also studied in the same monkeys. The experimental conditions for antagonism studies were the same as substitution studies with single doses of each antagonist administered prior to increasing doses of NMDA. Based upon results of preliminary drug discrimination studies the pretreatment time was $15 \mathrm{~min}$ for ketamine, $30 \mathrm{~min}$ for MK-801 and $2 \mathrm{~h}$ for CGS 19755. (These are the times for MK-801 and ketamine at which ketamine-appropriate responding occurred reliably. CGS 19755 failed to produce ketamine-appropriate responding and for studies of antagonism it was administered $15 \mathrm{~min}-24 \mathrm{~h}$ prior to NMDA.)

\subsection{Data analysis}

Drug discrimination data are expressed as the average percentage of responses on the ketamineappropriate lever for three monkeys. Drugs were considered to have substituted for ketamine if they produced at least $90 \%$ ketamine-appropriate responding. Response rate data are the average rates of responding among the three monkeys and are expressed as a percentage of the control (saline) response rate. These values were determined for individual subjects by dividing the response rate during test sessions by the average control response rate of 20 training cycles preceded by injections of saline and multiplying by 100 .

\subsection{Drugs}

The drugs used in this study were ketamine hydrochloride (Ketalar, Warner-Lambert/ParkeDavis), MK-801 ((+)-5-methyl-10,11-dihydro5H-dibenzo(a,d)cyclohepten-5,10-imine maleate; Merck, Sharp and Dohme, Westpoint, PA), CGS 19755 (1-(cis-2-carboxypiperidine-4-yl)methyl-1phosphonic acid; synthesized by P. Ornstein), and NMDA (N-methyl-D-aspartate; Sigma Chemical Co., St. Louis, MO). MK-801, CGS 19755 and NMDA were dissolved in sterile water. Sterile water also was used for diluting Ketalar solutions. All drugs were administered s.c. in the back and doses are expressed in terms of the salts $(\mathrm{mg} / \mathrm{kg}$ body weight). Injection volumes were $0.1 \mathrm{ml} / \mathrm{kg}$ for ketamine, MK-801 and NMDA and 0.1-0.4 $\mathrm{ml} / \mathrm{kg}$ for CGS 19755.

\section{Results}

Single injections of ketamine or MK-801 produced responding on the ketamine-appropriate lever in a dose-related manner and at larger doses decreased rates of responding maintained by the presentation of food (fig. 1). MK-801 was 32 times more potent than ketamine as a discriminative stimulus and 10-32 times more potent than ketamine in decreasing response rates. Various doses of CGS 19755 were studied using a variety of pretreatments using single and cumulative dosing procedures, and under no condition did CGS 19755 substitute for ketamine. For example, single doses of CGS 19755, up to a dose of $10.0 \mathrm{mg} / \mathrm{kg}$, produced responding exclusively on the saline lever and decreased rates of responding to $61 \%$ of control (fig. 1).

NMDA (1.0-10.0 mg/kg) produced no ketamine-appropriate responding (data not shown) and no observable behavioral effects up to doses that decreased rates of food-maintained responding (closed symbols, fig. 2). A dose of $1.0 \mathrm{mg} / \mathrm{kg}$ of NMDA did not affect response rates whereas a dose of $5.6 \mathrm{mg} / \mathrm{kg}$ of NMDA eliminated responding in two monkeys and the third monkey failed to respond at a dose of $10.0 \mathrm{mg} / \mathrm{kg}$ NMDA. The 

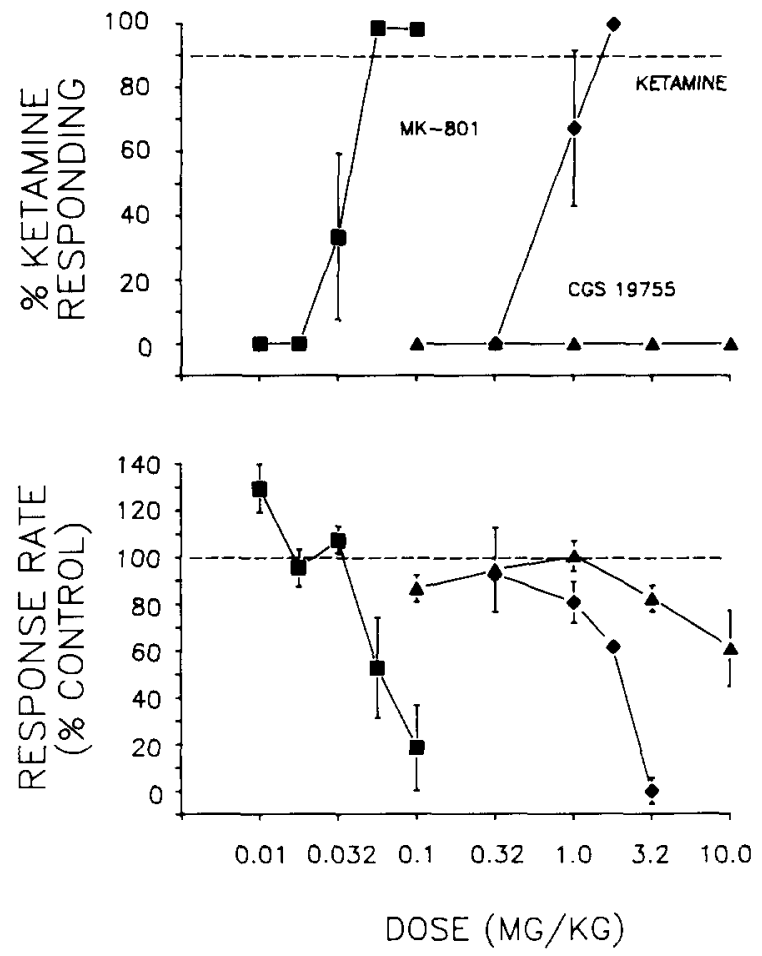

Fig. 1. Dose effect curves for ketamine, MK-801 and CGS 19755 in thesus monkeys discriminating between $1.78 \mathrm{mg} / \mathrm{kg}$ of ketamine and saline. Each point is the average of single determinations in each of three subjects. A single injection was administered immediately before (ketamine) or $15 \mathrm{~min}$ before (MK-801 and CGS 19755) the beginning of a test cycle. Ordinates: upper panel, average percentage of responses on the ketamine lever \pm 1 S.E.M.; lower panel, average response rate expressed as a percentage of the control (saline) response rate \pm 1 S.E.M. The average control response rates over 20 saline cycles for individual monkeys were $3.42 \pm 0.11,1.91 \pm$ 0.26 and $2.99 \pm 0.37$. Abscissas: dose in $\mathrm{mg} / \mathrm{kg}$ body weight.

discriminative stimulus effects of ketamine and MK-801 were not altered by NMDA and, therefore, only response rate data are presented from the antagonism studies. Doses of ketamine that decreased response rates when administered alone attenuated the rate-decreasing effects of NMDA (left panel, fig. 2). These doses of ketamine (1.0, 1.78 and $3.2 \mathrm{mg} / \mathrm{kg}$ ) did not alter markedly the rate-decreasing effects of a dose of $3.2 \mathrm{mg} / \mathrm{kg}$ of NMDA but did attenuate the effects of larger doses of NMDA such that doses larger than 5.6 $\mathrm{mg} / \mathrm{kg}$ of NMDA were required to eliminate re- sponding. A dose of $5.6 \mathrm{mg} / \mathrm{kg}$ of ketamine eliminated responding and this effect was not altered by the administration of $1.0 \mathrm{mg} / \mathrm{kg}$ of NMDA.

In contrast to the results obtained with ketamine, doses of MK-801 that did not decrease response rates attenuated the rate-decreasing effects of NMDA (center panel, fig. 2). Doses of 0.01 and $0.032 \mathrm{mg} / \mathrm{kg}$ of MK-801 did not decrease response rates when administered alone and shifted the dose-effect curve for NMDA 0.25 and $0.5 \log$ units to the right, respectively. A dose of $0.056 \mathrm{mg} / \mathrm{kg}$ of $\mathrm{MK}-801$ decreased response rates to approximately $50 \%$ of control rates; this dose of MK-801 administered in combination with $1.0 \mathrm{mg} / \mathrm{kg}$ of NMDA eliminated responding in all three monkeys.

CGS 19755 attenuated the rate-decreasing effects of NMDA in a dose- and time-related manner. When administered $2 \mathrm{~h}$ prior to increasing doses of NMDA, doses of 0.1 and $1.0 \mathrm{mg} / \mathrm{kg}$ of CGS 19755 antagonized the rate-decreasing effects of NMDA and shifted the NMDA dose-effect curve in parallel to the right (right panel, fig. 2). Whereas under control conditions responding was eliminated by a dose of $5.6 \mathrm{mg} / \mathrm{kg}$ of NMDA, $2 \mathrm{~h}$ after $1.0 \mathrm{mg} / \mathrm{kg}$ of CGS 19755 this dose of NMDA had no effect on response rates and a 3-fold larger dose of NMDA $(17.8 \mathrm{mg} / \mathrm{kg})$ was required to eliminate responding. A larger dose of CGS $19755,3.2 \mathrm{mg} / \mathrm{kg}$, did not produce additional antagonism of the rate-decreasing effects of NMDA.

The antagonistic actions of CGS 19755 were studied $15 \mathrm{~min}-24 \mathrm{~h}$ after administration of 3.2 $\mathrm{mg} / \mathrm{kg}$ of CGS 19755. Antagonism of the rate-decreasing effects of NMDA by CGS 19755 was greater when CGS 19755 was administered 15 min prior to NMDA than when longer pretreatment intervals were used (fig. 3). While a dose of 17.8 $\mathrm{mg} / \mathrm{kg}$ of NMDA eliminated responding $2 \mathrm{~h}$ after administration of $3.2 \mathrm{mg} / \mathrm{kg}$ of CGS 19755 , this dose of NMDA had no effect on response rates when CGS 19755 was administered $15 \mathrm{~min}$ prior to NMDA. Only a slight attenuation of the ratedecreasing effects of NMDA was observed $24 \mathrm{~h}$ after administration of a dose of $3.2 \mathrm{mg} / \mathrm{kg}$ of CGS 19755. 


\section{Discussion}

Monkeys discriminating between s.c. injections of ketamine and saline generalized to the noncompetitive EAA antagonist MK-801 but did not generalize to the competitive EAA antagonist CGS 19755 up to a dose of $10.0 \mathrm{mg} / \mathrm{kg}$. These data confirm previous reports on the discriminative stimulus effects of MK-801 in monkeys and other species (Koek et al., 1988; Willetts and Balster, 1988a) and extend results from a study in which another competitive EAA antagonist, AP5 (Watkins and Evans, 1981), failed to substitute for the ketamine discriminative stimulus when given systemically in monkeys (Woods et al., 1987). Results of the present study also are consistent with previous demonstrations (e.g. Willetts and Balster, 1988b) on the lack of antagonism by NMDA of the discriminative stimulus effects of non-competitive antagonists.

The pretreatment times for ketamine and MK801 used in the NMDA antagonism study were selected so as to be able to compare these compounds at a time when they produced unequivocal ketamine-like discriminative stimulus effects. Full substitution (i.e. $>90 \%$ ) for the ketamine discriminative stimulus obtained with MK-801 in the present study using a $30-\mathrm{min}$ pretreatment sug-

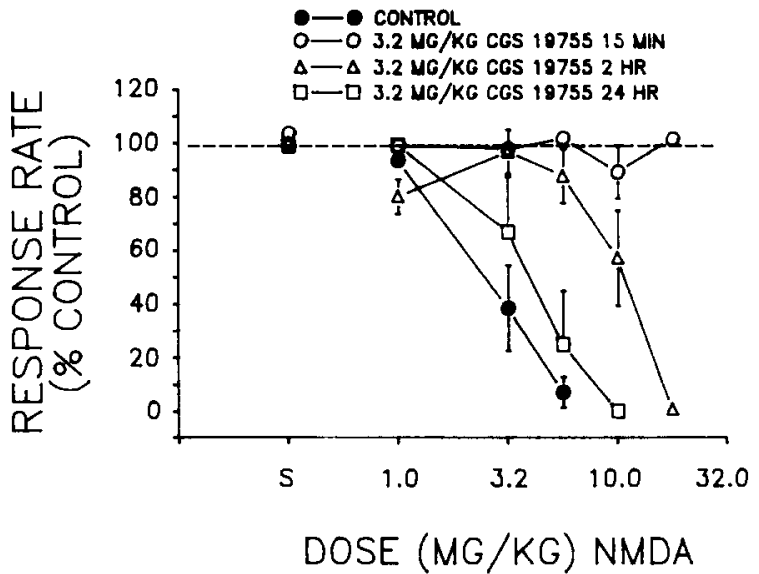

Fig. 3. Rate-decreasing effects of cumulative doses of NMDA administered alone (closed symbols) and when administered 15 $\mathrm{min}, 2 \mathrm{~h}$ and $24 \mathrm{~h}$ after administration of $3.2 \mathrm{mg} / \mathrm{kg}$ of CGS 19755. Data points above $S$ represent the effects of saline after pretreatment with CGS 19755. See fig. 1 for other details.

gests the partial substitution reported for ketamine in a previous report (Koek et al., 1988) might have resulted from the temporal conditions used to study discriminative stimulus effects (i.e. 10-min pretreatment). Because CGS 19755 did not produce ketamine-appropriate responding, it was not possible to equate temporal parameters of
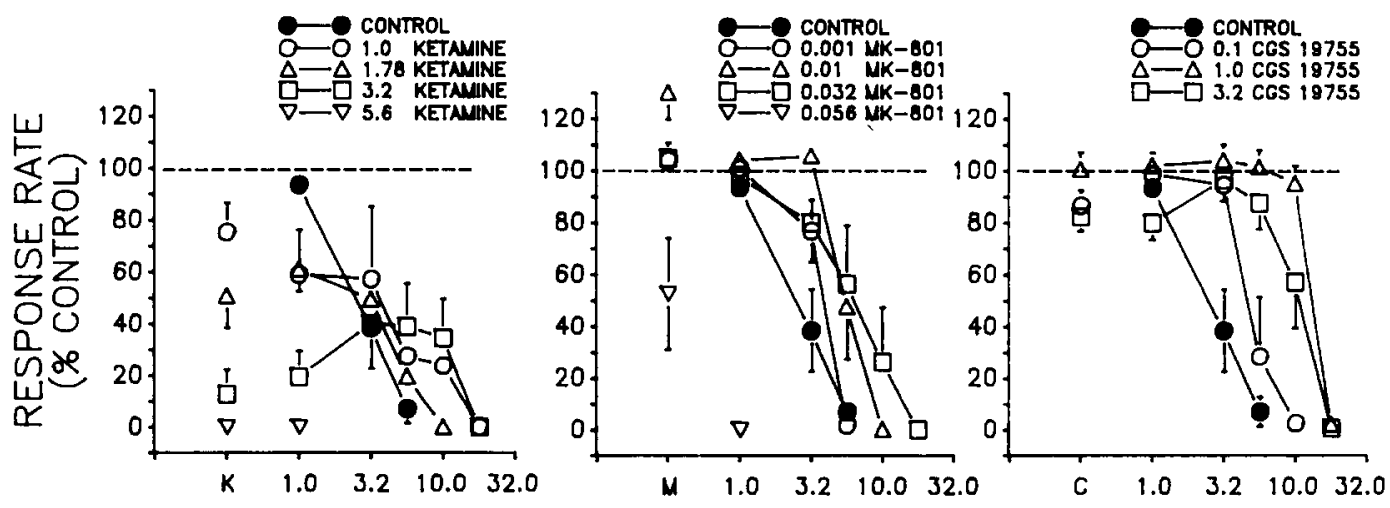

DOSE (MG/KG) NMDA

Fig. 2. Rate-decreasing effects of cumulative doses of NMDA administered alone (closed symbols) and after single injections of ketamine (left), MK-801 (center) or CGS 19755 (right). Data points above K, M, and C represent the effects of ketamine, MK-801, and CGS 19755 administered alone. The pretreatment time was $15 \mathrm{~min}$ for ketamine, $30 \mathrm{~min}$ for MK-801 and $2 \mathrm{~h}$ for CGS 19755 . See fig. 1 for other details. 
these testing conditions. Based upon preliminary studies in pigeons (S. Baron, personal communication) that indicated a slow onset of action for CGS 19755 , a 2 h pretreatment was used initially with CGS 19755 in rhesus monkeys. It is clear, however, from the time course study with a dose of $3.2 \mathrm{mg} / \mathrm{kg}$ of CGS 19755 that antagonism of the rate-decreasing effects on NMDA can be obtained within $1 \mathrm{~h}$ of administration of CGS 19755. While it is possible that doses of CGS 19755 larger than $10.0 \mathrm{mg} / \mathrm{kg}$ might produce ketamine-appropriate responding, it is clear that doses of CGS 19755 and MK-801 $(0.01 \mathrm{mg} / \mathrm{kg})$ that did not produce ketamine-appropriate responding attenuated the behavioral effects of NMDA. Moreover, the rate-decreasing effects obtained with a dose of $10.0 \mathrm{mg} / \mathrm{kg}$ of CGS 19755 suggest larger doses of CGS 19755 might decrease further or eliminate food-maintained responding.

CGS 19755 clearly antagonizes the behavioral actions (e.g. rate-decreasing effects) of NMDA in rhesus monkeys and this effect probably indicates that systemically administered CGS 19755 accesses NMDA receptors in brain. However, under conditions in which CGS 19755 antagonizes the rate-decreasing effects of NMDA it does not produce discriminative stimulus effects comparable to MK-801, ketamine and other non-competitive NMDA antagonists. Further studies might demonstrate similarities in the discriminative stimulus effects of competitive and non-competitive NMDA antagonists, however, in the absence of evidence in support of this notion, it might be supposed that in humans the subjective effects of non-competitive NMDA antagonists will be different from the subjective effects of competitive antagonists. The lack of ketamine-like discriminative stimulus effects of CGS 19755 raises interesting questions regarding the conditions under which competitive NMDA antagonists can be used to maintain discriminative control and the relation of these training conditions to conditions wherein the same antagonists prevent the behavioral actions of NMDA. Competitive antagonists at opioid receptors (e.g. naltrexone) can be utilized over a large range of non-discriminable doses to prevent the behavioral effects of opioid agonists (France and Woods, 1985; 1988).

\section{Acknowledgements}

The authors are grateful to L. Konrad for technical assistance and to R.J. McLaughlin and D. Robinson for assistance in preparing the manuscript. This research was supported by USPHS Grant DA-06325.

\section{References}

Balster, R.L. and J. Willetts, 1988, Receptor mediation of the discriminative stimulus properties of phencyclidine and sigma-opioid agonists, in: Transduction Mechanisms of Drug Stimuli, eds. F.C. Colpaert and R.L. Balster (Springer-Verlag, Berlin) p. 122.

Bennett, D.A., P.S. Bernard, C.C. Amrick, D.E. Wilson and A.J. Hutchinson, 1987, The behavioral pharmacological profile of an N-methyl-D-aspartate (NMDA) antagonist, CGS 19755, Soc. Neurosci. Abstr. 13, 561.

Boast, C.A., S.C. Gerhardt, G. Pastor, J.C. Lehmann, P.E. Etienne and J.M. Liebman, 1987, A comparison of two $\mathrm{N}$-methyl-D-aspartate antagonists, CPP and CGS 19755, in the gerbil forebrain ischemia model, Soc. Neurosci. Abstr. $13,497$.

France, C.P. and J.H. Woods, 1985, Antagonistic and rate-suppressing effects of opioid antagonists in the pigeon, $J$. Pharmacol. Exp. Ther. 235, 442.

France, C.P. and J.H. Woods, 1988, Acute supersensitivity to the discriminative stimulus effects of naltrexone in pigeons, J. Pharmacol. Exp. Ther. 244, 599.

Koek, W. and J.H. Woods, 1988, Correlations between phencyclidine-like activity and $\mathrm{N}$-methyl-D-aspartate antagonism: behavioral evidence, in: Sigma and PhencyclidineLike Compounds as Molecular Probes in Biology, eds. E.F. Domino and J.-M. Kamenka (NPP Books, Ann Arbor) p. 357.

Koek, W., J.H. Woods and G.D. Winger, 1988, MK-801, a proposed non-competitive antagonist of excitatory amino acid neurotransmission, produces phencyclidine-like behavioral effects in pigeons, rats, and rhesus monkeys, J. Pharmacol. Exp. Ther. 245, 969.

Lehmann, J., A.J. Hutchinson, S.E. McPherson, C. Tsai, C.M. Sinton, D. Murphy, M. Williams, D.J. Steel and P.L. Wood, 1987, A new potent NMDA-type receptor antagonist CGS 19755, Soc. Neurosci. Abstr. 13, 382.

Watkins, J.C. and R.H. Evans, 1981, Excitatory amino acid transmitters, Ann. Rev. Pharmacol. Toxicol. 21, 165.

Willetts, J. and R. Balster, 1988a, Phencyclidine-like discriminative stimulus properties of MK-801 in rats, European J. Pharmacol. 146, 167.

Willetts, J. and R.L. Balster, 1988b, Role of N-methyl-Daspartate receptor stimulation and antagonism in phencyclidine discrimination in rats, in: Sigma and Phencyclidine-Like Compounds as Molecular Probes in Biology, eds. E.F. Domino and J.-M. Kamenka (NPP Books, Ann Arbor) p. 397. 
Wong, E.H.F., J.A. Kemp, T. Priestley, A.E. Knight, G.M. Woodruff and L.L. Iversen, 1986, The anticonvulsant MK801 is a potent $\mathrm{N}$-methyl-D-aspartate antagonist, Proc. Natl. Acad. Sci. U.S.A. 83, 7109.

Woods, J.H., W. Koek and P. Ornstein, 1987, A preliminary study of PCP-like behavioral effects of 2-amino-5-phosphonovalerate in rhesus monkeys, in: Excitatory Amino Acid Transmission, eds. T.P. Hicks, D. Lodge and H. McLellan (Alan R. Liss, New York) p. 205. 